\title{
ELASTIC-PLASTIC CALCULATION OF A DILATATION COMPENSATION COMPONENT
}

\author{
ATANASIU Costică \\ professor emeritu, Ph.D., Faculty of Engineering and Management of Technological Systems, \\ Departament Strength of Materials, Politehnica University of Bucharest, Romania, e-mail : \\ atanasiucostica@yahoo.com \\ ILIESCU Nicolae \\ professor emeritus, Ph.D., Faculty of Engineering and Management of Technological Systems, \\ Departament Strength of Materials, Politehnica University of Bucharest, Romania, e-mail: \\ nviliescu@yahoo.com
}

\section{SOROHAN Ștefan}

professor, Ph.D., Faculty of Engineering and Management of Technological Systems, Departament Strength of Materials, Politehnica University of Bucharest, Romania,e-mail: fanes777@yahoo.com

\begin{abstract}
Compensators are elastic structures that have the role of taking over the axial displacements that occur in the junction areas of the technological equipment (pipelines or containers) through which the fluids circulate at pressures and high temperatures. These elastic structures, realized in a very wide range of shapes and sizes, are sujected by the inner pressure and an axial force produced by dilatation of structures in which they are mounted. The calculation of the expansion compensators raises many problems caused by the working regimes of the technological equipments they belong to. Following previous studies, undertaken by calculus and experimental, by the authors of this paper, it was found that in operation the state of stress in these elastic structures exceeds the flow limit of the material from which they are manufacturated. For this reason, in the present paper, the authors present the results of a calculus study, by FEM, on the stress and strain state, in the elasto-plastic regime of a leticular compensator. The calculation was made for two loading modes, separately applied and superimposed. The nonlinear mechanical behavior of this compensator is analyzed and discussed comparatively to the results of previous studies performed in elastic regime on the same type of compensator.
\end{abstract}

Key words: compensator, elastoplastic field, finite element, stress

\section{Introduction}

In the architecture of some equipment and installations in the process industry [4], district heating, aeronautics, civil or industrial construction, a series of elastic structures, called compensators, are interleaved with the role of taking over the axial displacements due to the technological process in which their are included. During operation, the compensators are subjected to the internal pressure of the fluid flowing through the installation and to an axial force produced by the expansion of the structures in which they are interconnected. Because of the complicated geometric shapes they can have, the analysis of stress and strain states in these elastic structures is complex, especially in areas of sudden variation in curves, where strong stress concentrations occur [6]. In Figure 1 is presented a lenticular compensator [1], [2], [3] commonly encountered in the structure of industrial equipments. In some situations these elements work in the non-elastic field. Therefore, the paper presents an analysis of the mechanical behavior in the nonlinear domain of these structures. 


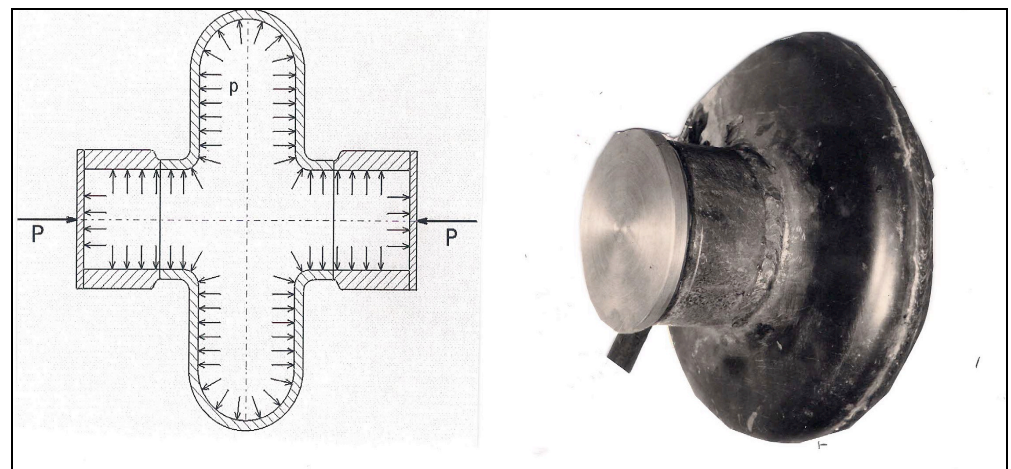

Figure1: The lenticular compensator Source: authors

\section{Calculus in the elastoplastic field by FEM}

The calculation was made for the leticular compensator of Figure 1, made of steel sheet with the thickness $\mathrm{h}=2.5 \mathrm{~mm}$, with the outer diameter $\mathrm{D}=334 \mathrm{~mm}$, the inner diameter $\mathrm{d}=145 \mathrm{~mm}$ and the tangential coating connections, $\mathrm{r} 1=23 \mathrm{~mm}$ and $\mathrm{r} 2=21 \mathrm{~mm}$. For computation, the compensator was considered to be loaded with the internal pressure $\mathrm{p}=0,9 \mathrm{MPa}$ and an axial compressive force $\mathrm{F}=30 \mathrm{kN}$, applied in two variants: discharged,

1. Loading, first, with internal pressure and then with axial force, after which the compensator is discharge.

2. Loading, first, with axial force and then with internal pressure, after which then compensator

Nonlinear analysis was performed with the ANSYS 13.0 program [5] considering both large displacements and material nonlinearities. For reasons of symmetry, the calculation was made only for half the model. In Figure 2 the calculation model is presented.
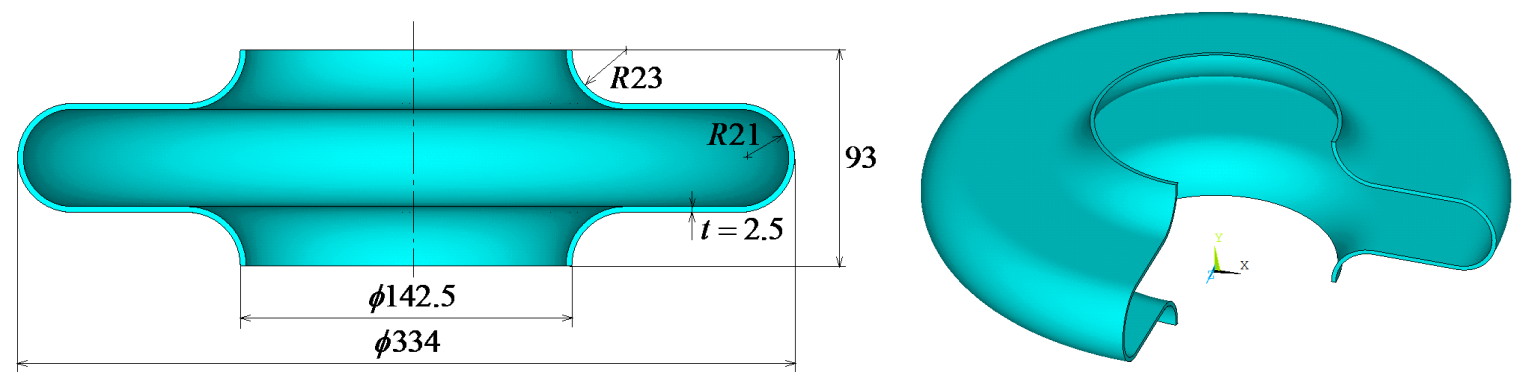

Figure 2: Calculation model of the analyzed compensator Source: authors

In Figure 3 is presented the bi-linear schematic characteristic curve, based on experimentally determined data, for the compensator material. The model was meshed with four-quadrant elements with eight nodes. On the thickness of the shell were considered 10 rows of elements, resulting in 5060 elements and 16213 nodes. 
ACTA UIVERSITATIS CIBINIENSIS - TECHNICAL SERIES

Vol. LXIX 2017

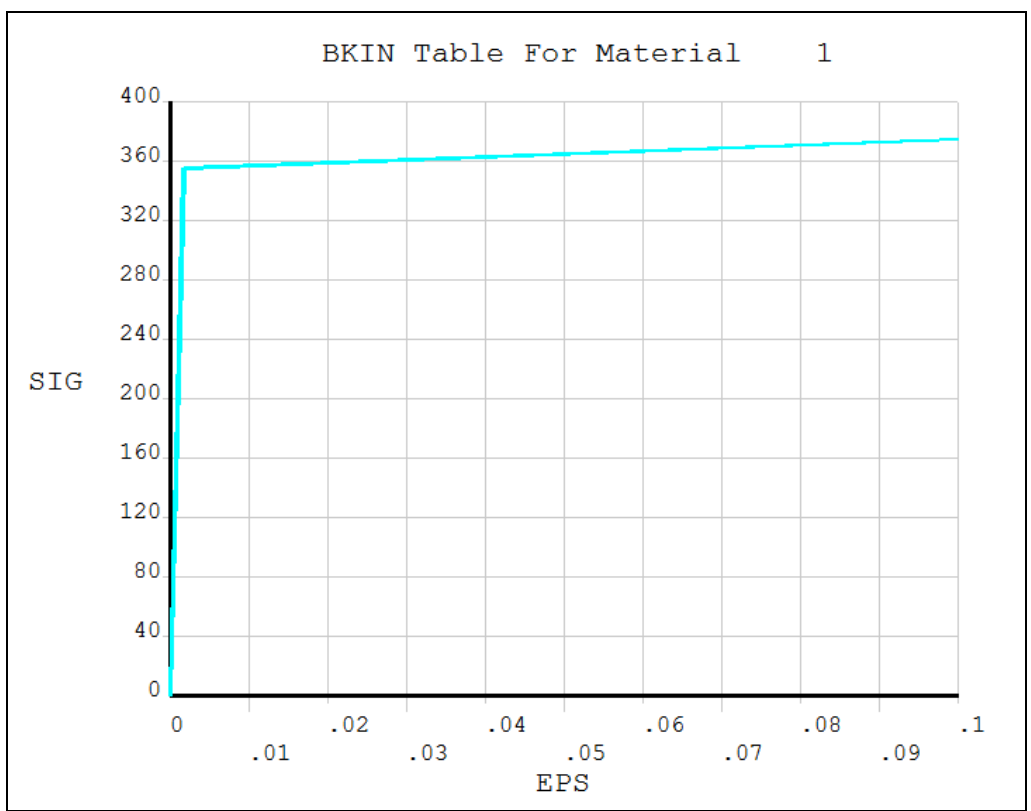

Figure3: The schematic characteristic curve used in the calculation Source: authors

Figure 4 shows how to apply loads (times 1, 2 and 3 ) for the two load modes. Time 0 corresponds to a structure without permanent deformations, and time 3 corresponds to complete unloading.

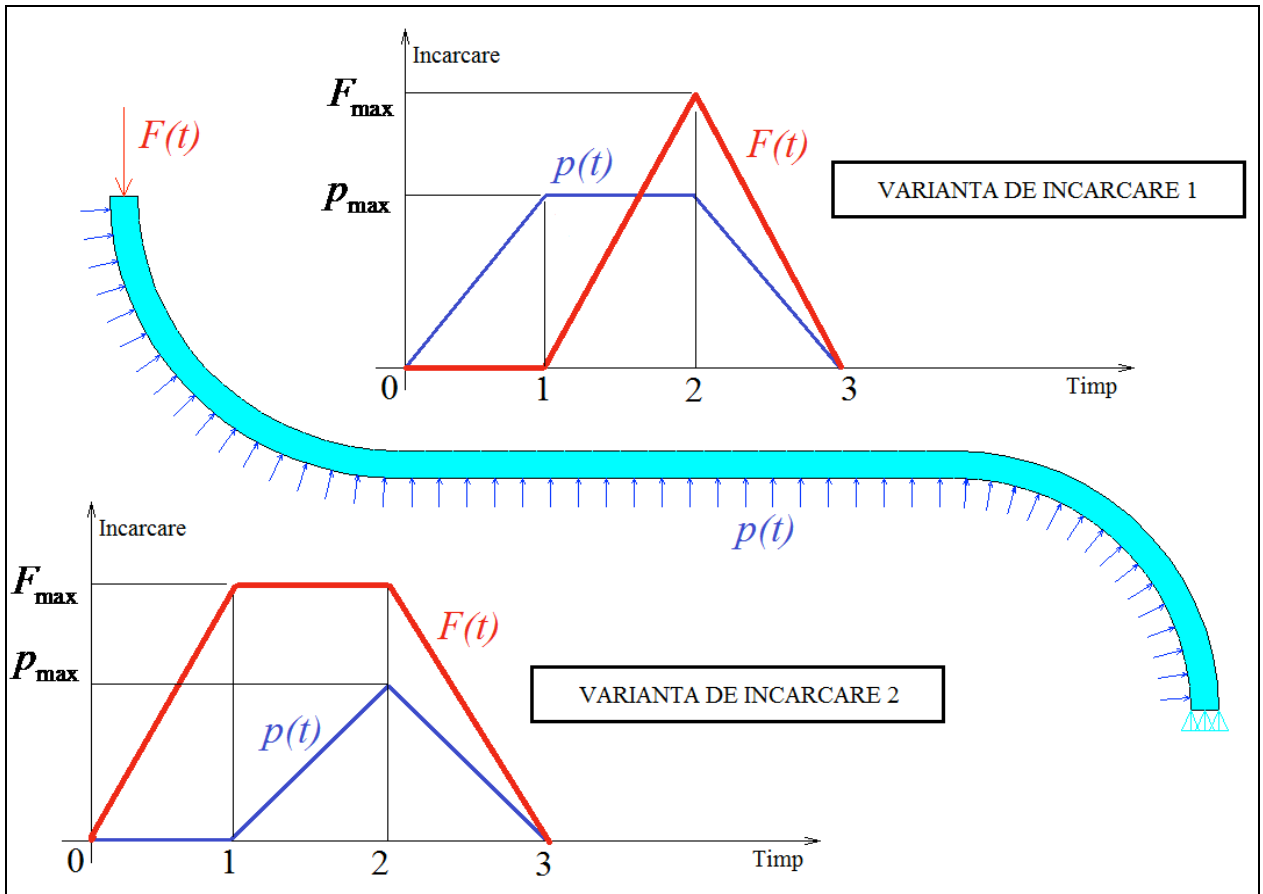

Figure 4: Calculation model and load variants

Source: authors 
ACTA UIVERSITATIS CIBINIENSIS - TECHNICAL SERIES

Vol. LXIX 2017

From the examination of the results obtained from the simulations made on the calculation model, it is found that the maximum displacement of the concentrated load application section is much higher for the load variant 2 (Figure 5, a) than for the loading variant 1 (Figure 5, b) resulting at discharges a permanent displacements of $-14.3 \mathrm{~mm}$ and $-1.6 \mathrm{~mm}$ respectively.

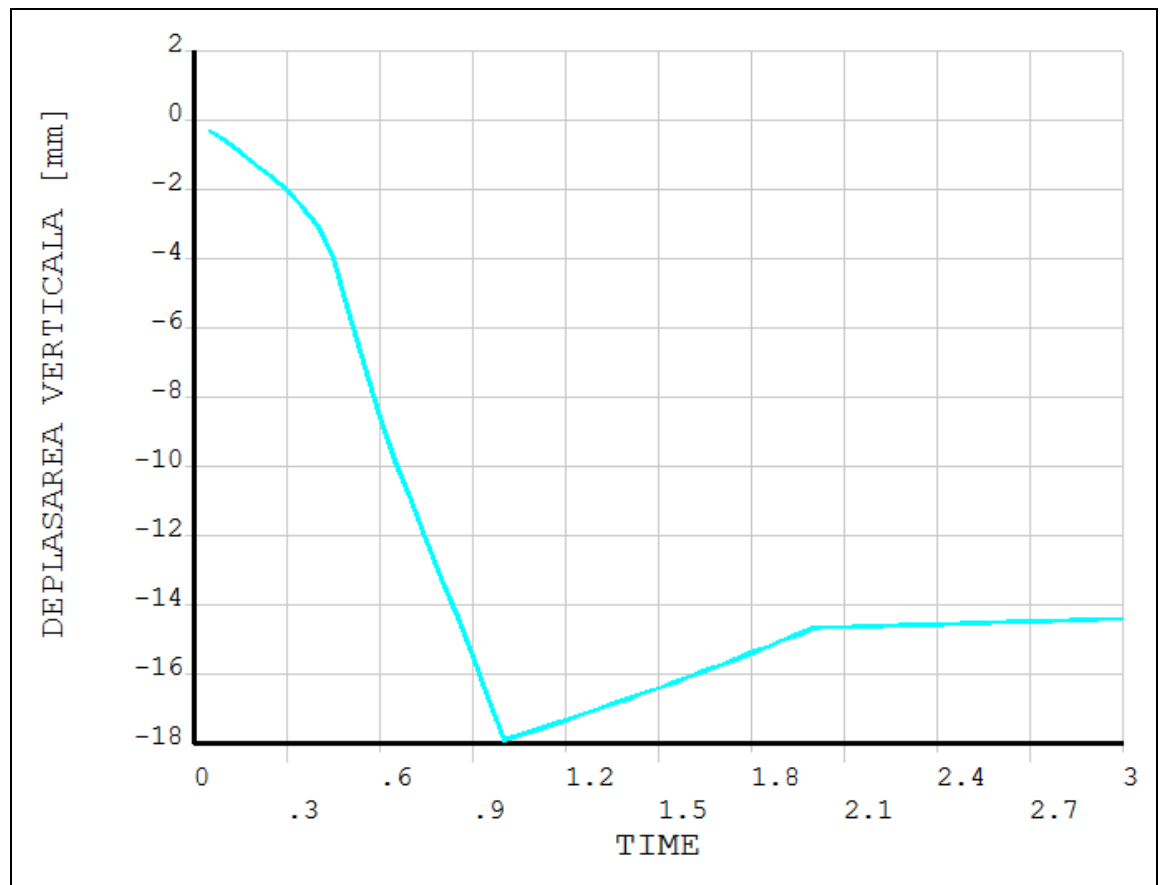

Figure 5 a.: Displacement of the concentrated force application section in load variant 2 Source: authors

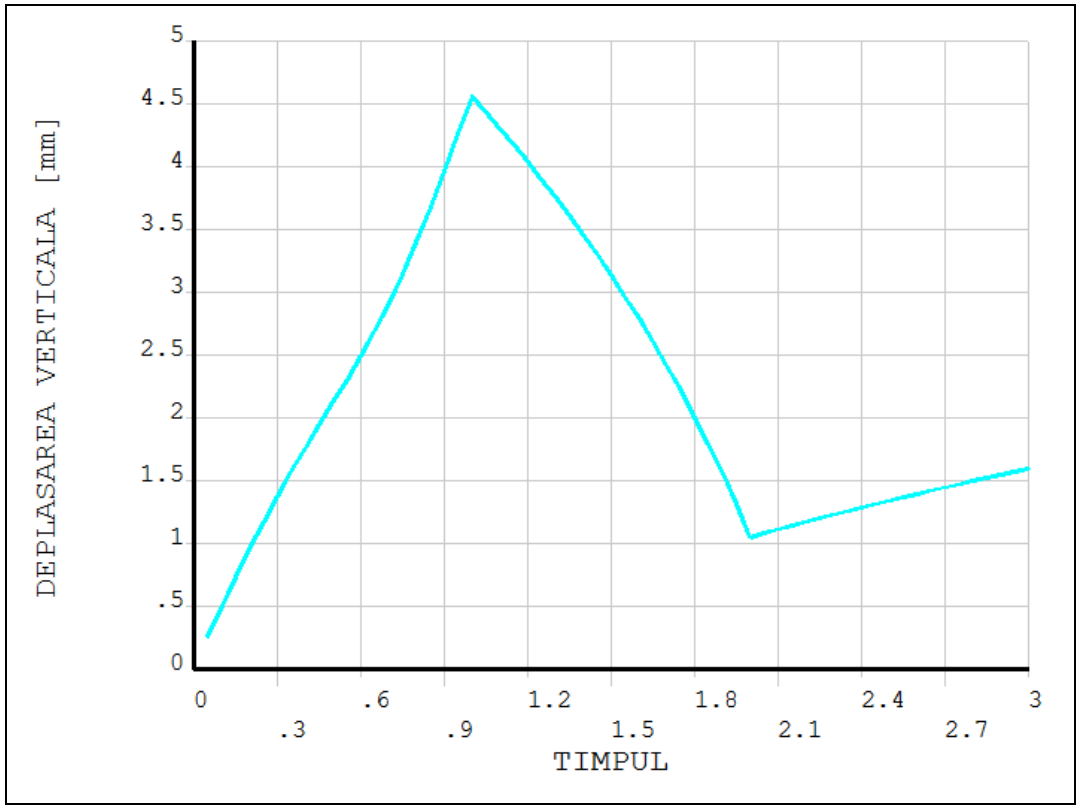

Figure 5 b.: Displacement of the concentrated force application section in load variant 1

Source: authors

This situation leads to strains and von Mises stresses higher at discharge in load version 2. It can also be seen, in both cases, that the deplacement variation in time travel deviates slightly from linearity and the 
ACTA UIVERSITATIS CIBINIENSIS - TECHNICAL SERIES

Vol. LXIX 2017

discharge is linear. Stresses are higher in loading variante 2. By first applying of the concentrated force (Figure 6, a), the von Mises equivalent stresses, reach values exceeding the yielding limit of the material (382.7 MPa) throughout the shell. This distribution changes by applying the internal pressure, which acts in the opposite direction to the concentrated force. It is found that thestresses record high values (377.2 $\mathrm{MPa}$ ) only in the middle of the annular plate and the inner torus (Figure 6, b). When discharging permanent stresses with a maximum value of $336 \mathrm{MPa}$, they only appear in the middle of the annular plate and the inside torque (Figure $6 \mathrm{c}$ ).

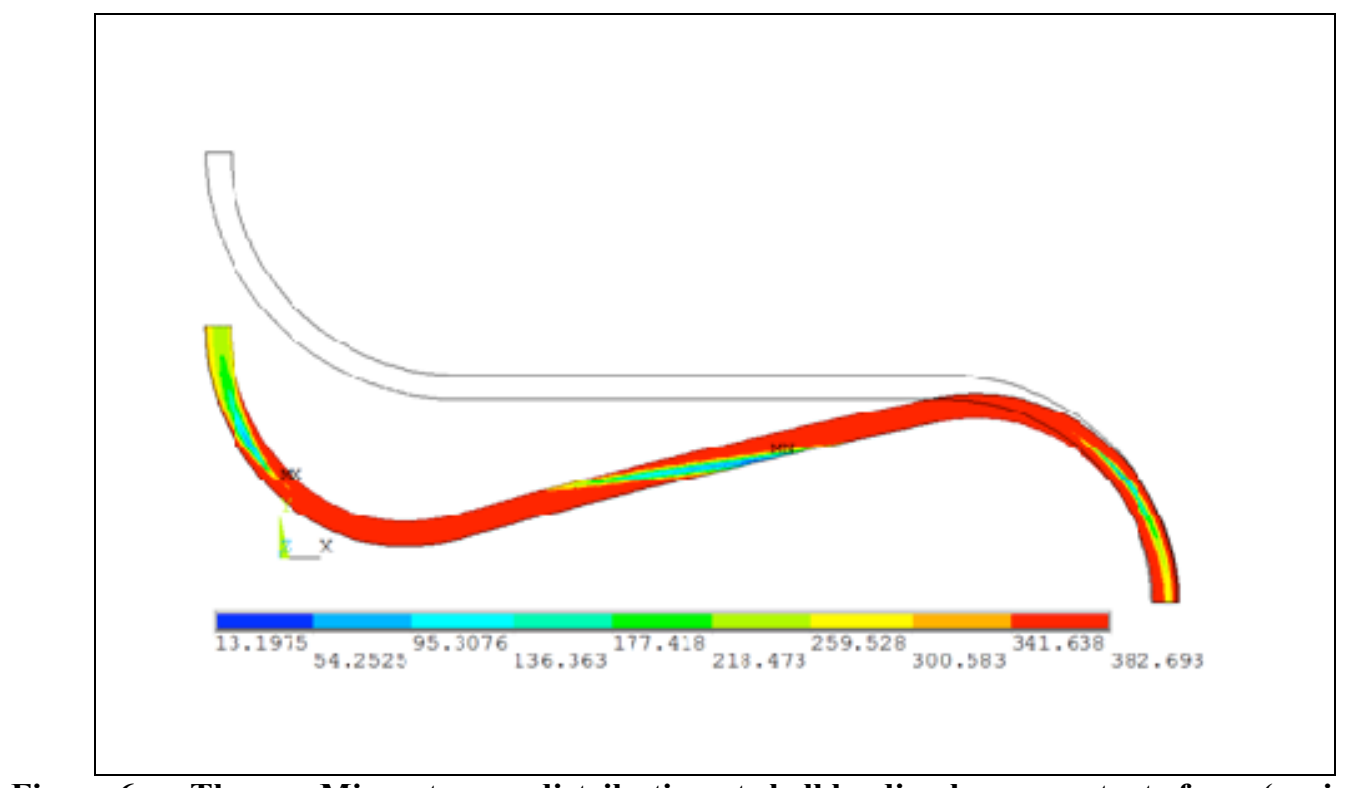

Figure 6 a.: The von Mises stresses distribution at shell loading by concentrate force (variant 2) Source: authors

Figure 6 b.: The distribution of the von Mises stresses produced by the concentrated force and the inner pressure in the shell (var. 2)

Source: authors 
ACTA UIVERSITATIS CIBINIENSIS - TECHNICAL SERIES

Vol. LXIX 2017

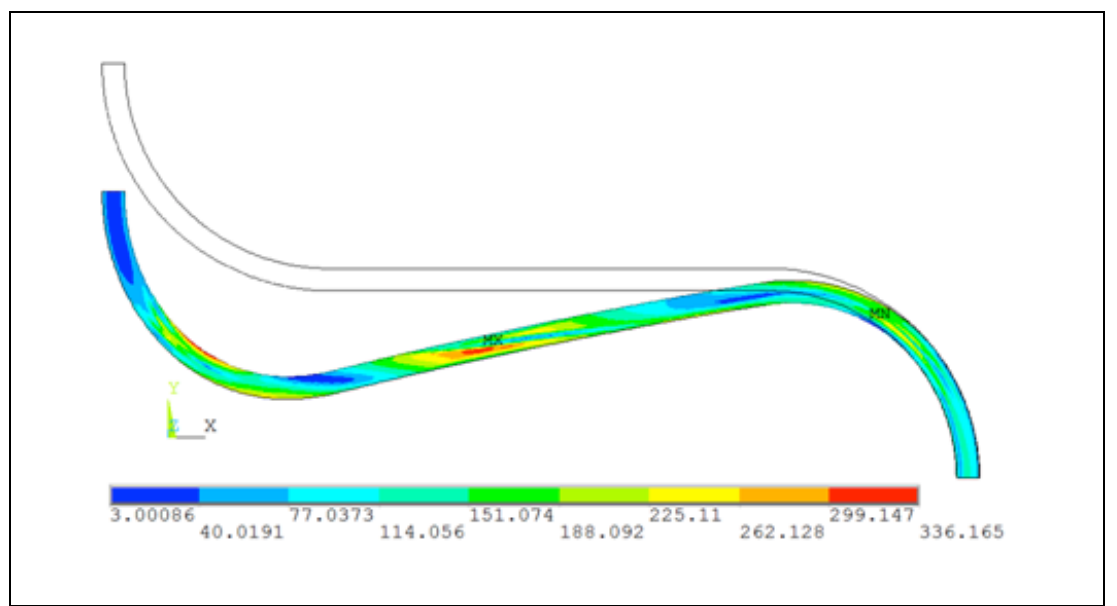

Figure 6 c.: The Von Mises stresses distribution at discharge (variant 2)

Source: authors

For variant 1, when first the internal pressure is applied, the maximum stresses of $371.3 \mathrm{MPa}$ are produced, especially on the toroidal surfaces (Figure 7. a). These stresses are maintained in the same area at $354.9 \mathrm{MPa}$ when the counter-concentrated force acts (Figure7, b). At discharge it is observed that maximum stresses of $319.6 \mathrm{MPa}$ are also produced in the torque-plate connection zones (Figure 7. c).

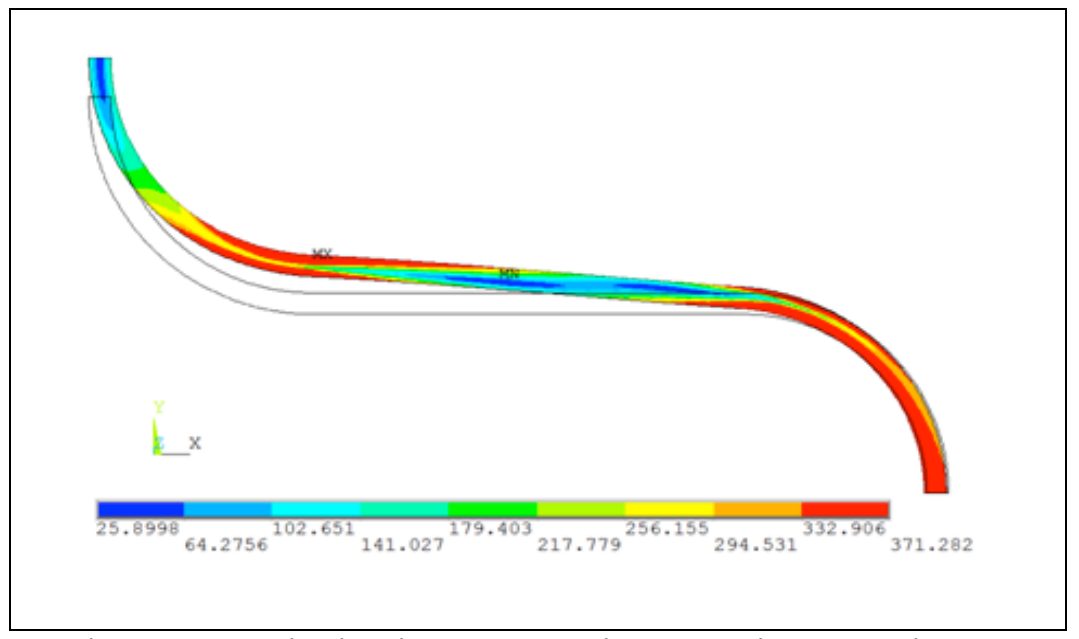

Figure 7 a.: The von Mises stresses distribution produced in the coating by the internal pressure (variant 1) Source: authors

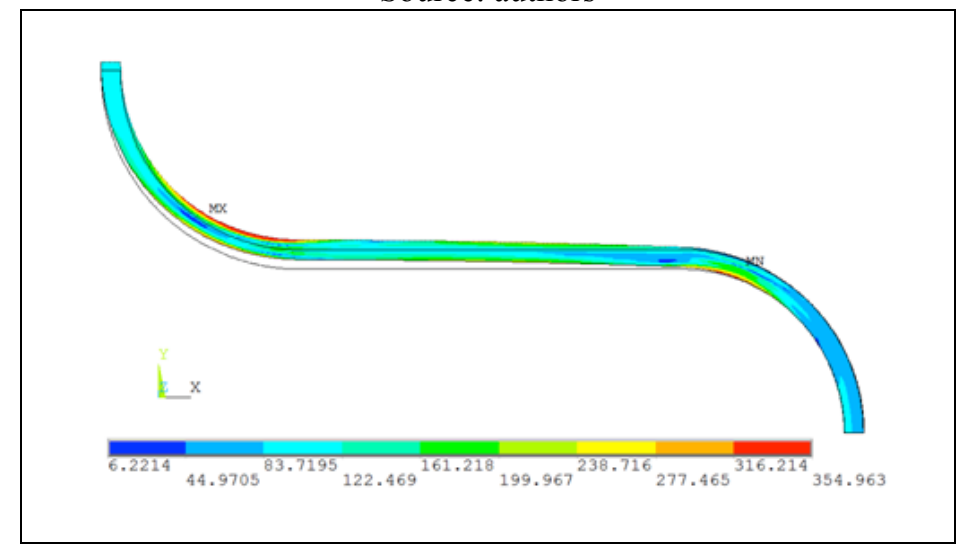

Figure 7 b.: The von Mises stresses distribution produced in the coating by the inner pressure and concentrated force (variant 1$)$ 
ACTA UIVERSITATIS CIBINIENSIS - TECHNICAL SERIES

Vol. LXIX 2017

Source: authors

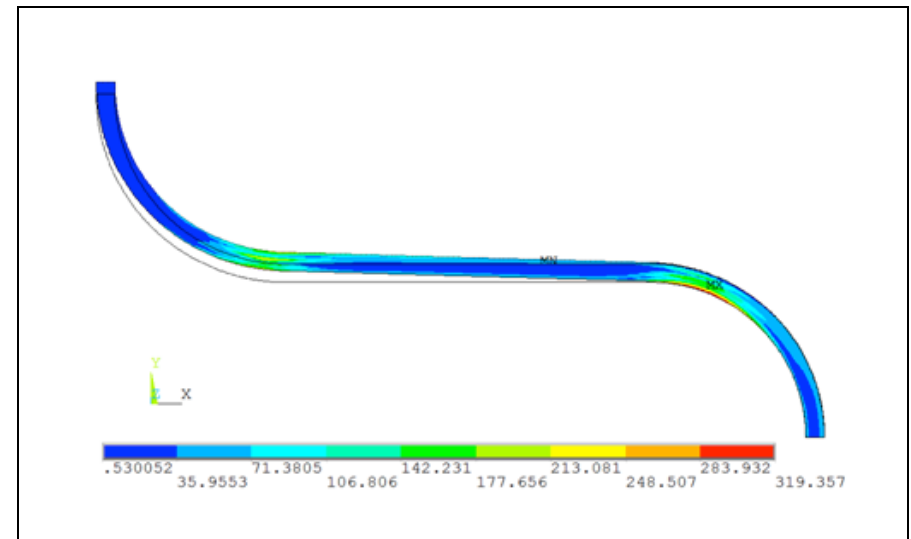

Figure 7 c.: The von Mises stresses distribution produced in the coating in the unloading (variant 1) Source: authors

\section{Conclusions}

Following of the undertaken study it was found that by combined action the two loads, in both loading variants, the maximum stresses produced in the analyzed structure are below of the material yielding limit on most of the coating. These stresses exceed the yielding limit of the material in zones of connection of the shell and at full discharge their values are just below this limit. In operation, by repeated charging and discharging of the equipment in which the compensator is inserted, the material is ecruising and thereby increasing its loading capacity. The results of this study show that areas where high stresses values were recorded, coincide with those identified in previous studies, undertaken by computationally in the elastic material behavior field, or experimental. The analyzes carried out within these researches can be considered as stages of a working methodology for investigating the stress and strain state of the connected shells

\section{References}

1. Atanasiu, C., Iliescu, N., Hadăr, A., Stress Distribution in Expansion Lens Joints, Revista de Chimie, vol. 56, Nr.1, Bucharest, Romania (2009)

2. Atanasiu, C., Iliescu, N.,Sandu,A., Cercetări privind starea de tensiune în structuri formate din plăci plane și curbe subțiri, Universitatea Tehnică a Moldovei, A XXIV-a Conferință Națională de Mecanica solidelor, Buletin științific, vol.1, pag. 33-36, Chișinău, Republica Moldova ( 2000)

3. Atanasiu, C., Baciu, F., Vlăsceanu, D., Drăghici, S., The Stress Distribution in a Filleted Shell, 25-th DanubiaAdria Symposium on Advanced in Experimental Mechanics, pag. 3-4, Ceskie Budejovice, Cehia (2009)

4. Jinescu, V., Utilaj tehnologic pentru industria de proces, Editura Tehnică București, România (1989)

5. Sorohan, Șt., Elemente finite în ingineria mecanică, Editura Politehnica, București, România (2015)

6. Timoshenko, S., Woinowski, K., Theory of Plates and Shell, Mc Graw-Hill Book Company Inc. New York,USA (1959) 